\title{
Proteínas no sangue de índios Terena de Mato Grosso do Sul - Brasil
}

\section{Proteins in the blood of Terena Indians of Mato Grosso do Sul (State) - Brazil}

\author{
Petr Melnikov; Wander Fernando de Oliveira Filiú2; Sandra Maura Aguena ${ }^{3}$ \\ Médico, Químico. Doutor em Química, Professor da Faculdade de Medicina Dr. Hélio Mandetta, UFMS. \\ Professor do Programa de Pós-Graduação Stricto Sensu em Saúde e Desenvolvimento para a Região Centro-Oeste - UFMS. \\ 2 Farmacêutico Bioquímico, Mestre em Biologia Parasitária - FIOCRUZ. Professor de Bioquímica Clínica do Departamento de \\ Farmácia Bioquímica - UFSM. \\ ${ }^{3}$ Farmacêutica Bioquímica - Laboratório de Analises Clínicas, Hospital Universitário, UFMS
}

Endereço para correspondência

Wander Fernando de Oliveira Filiú

Rua Pernambuco, 946 ap. 802 - Monte Castelo

79010-900 - Campo Grande - MS [Brasil

wfiliu@terra.com.br

\begin{abstract}
Resumo
A participação dos indígenas brasileiros no espaço socioeconômico mais amplo implica abandono de hábitos originais e mudanças na sua alimentação. Apesar da existência de programas especiais que provêem assistência, a ideia geral que persiste na opinião pública é que essas comunidades são socialmente abandonadas e economicamente desfavorecidas. Proteínas do sangue estão entre os marcadores bioquímicos que permitem uma avaliação objetiva do estado de saúde de um indivíduo. O objetivo deste estudo foi determinar as proteínas no sangue de 285 índios Terena saudáveis que habitam o Estado de Mato Grosso do Sul, Brasil. As concentrações no soro de homens e mulheres foram, respectivamente, 7,48 $( \pm 0,46)$ e $7,42( \pm 0,58) \mathrm{g} / \mathrm{dl}$ de proteínas totais e $4,33 \mathrm{~g} / \mathrm{dl}( \pm 0,36)$ e $4,17 \mathrm{~g} / \mathrm{dl}( \pm 0,37)$ de albumina. Conclui-se, do ponto de vista bioquímico, que os índios Terena estudados não mostram nenhuma anormalidade no metabolismo protéico e não podem ser considerados como um grupo subnutrido.
\end{abstract}

Descritores: Albumina; Índios Terena; Proteínas totais.

\begin{abstract}
The Brazilian aborigine's participation in a wider social-economic space implies giving changes in their nourishment patterns. In spite of the existence of the special programmers providing assistance, a general idea about these populations as abandoned and economically disadvantaged still persists in public opinion. Blood proteins are among the biochemical markers which allow an objective evaluation of the health status of an individual. The purpose of the present study was to determine proteins in the blood of 285 healthy Terena Indians inhabiting the State of Mato Grosso do Sul, Brazil. The average concentrations in serum of men and women respectively were 7,48 $( \pm 046)$ and 7,42 $( \pm 0,58) \mathrm{g} / \mathrm{dl}$ of total proteins and $4,33 \mathrm{~g} / \mathrm{dl}( \pm 0,36)$ e $4,17 \mathrm{~g} / \mathrm{dl}( \pm 0,37)$ of albumin. It is concluded that from the biochemical point of view Terena Indians show no abnormalities in protein metabolism and cannot be considered as a sub nourished group.
\end{abstract}

Key words: Albumins; Terena Indians; Total proteins. 


\section{Introdução}

As populações indígenas no mundo são diversificadas e geograficamente dispersas. Estão presentes em todos os continentes, inclusive nas regiões mais inóspitas, próximas aos pólos, e nas florestas tropicais como a amazônica e a africana. De acordo com o censo de 2000, estima-se que 2,7 milhões da população dos Estados Unidos compõem-se de índios e nativos do Alasca ou seus descendentes ${ }^{1}$. A população indígena no Brasil soma 488.441 habitantes, perfazendo $0,25 \%$ da população brasileira. Estima-se que existam ainda de 100 a 190 mil indivíduos vivendo fora das terras indígenas, inclusive em áreas urbanas ${ }^{2}$.

Apesar da existência de múltiplos programas da assistência ao índio, coordenados pela Fundação Nacional do Índio (Funai) e pela Fundação Nacional de Saúde (Funasa) que, desde 1999, implementa a política de saúde para os povos indígenas, a ideia geral que persiste na opinião pública é que essas comunidades são socialmente abandonadas e economicamente desfavorecidas.

De acordo com os dados oficiais da Funai ${ }^{3}$ para 2008, o Estado de Mato Grosso do Sul, localizado na região Centro-Oeste do Brasil, é tido como a sede da segunda maior população indígena do Brasil. Conta com 32.519 indígenas, povoando 46 aldeias. Os Terenas, com uma população estimada em 16 mil pessoas, vivem atualmente em um território descontínuo, fragmentado em pequenas "ilhas" cercadas por fazendas e espalhadas por sete municípios sul-mato-grossenses: Miranda, Aquidauana, Anastácio, Dois Irmãos do Buriti, Sidrolândia, Nioaque e Rochedo.

Com o inevitável envolvimento das populações indígenas no espaço socioeconômico do País, ocorre o abandono de certos hábitos originais e mudanças na estrutura da sua alimentação, mesmo que muitas práticas da vida cotidiana permanecem ainda relativamente intactas.

Onís e colaboradores ${ }^{4}$ relatam que a maioria das publicações relativas à saúde indígena refere-se aos dados antropométricos e nutricionais, principalmente das crianças, sempre mencionando a necessidade de relacioná-los ao perfil bioquímico. Poucos estudos tratam dos parâmetros bioquímicos propriamente ditos, entre os quais a hemoglobina glicosilada ${ }^{5}$, glicemia capilar ${ }^{6}$, colesterol total e frações, triglicérides e ácido úrico ${ }^{7}$, e outros menos importantes.

É evidente a falta de informação sobre a quantificação das proteínas, um dos mais relevantes marcadores bioquímicos ideais à nutrição e à saúde de modo geral. Consequentemente, a ingestão alimentar insuficiente causa a desnutrição energético-proteica. Posto que essa condição leva a redução tanto das reservas de gordura quanto da massa magra corporal, a procura por métodos capazes de efetivamente quantificar essa depleção sempre existe. As proteínas, por suas características físico-químicas, apresentam as seguintes funções fisiológicas: nutritiva, estrutural, enzimática, oncótica, hormonal e imunológica. Participam também na regulação do $\mathrm{pH}$, na coagulação sanguínea e no transporte de moléculas bioativas ${ }^{8}$.

A albumina é sintetizada exclusivamente pelo fígado. Entre $12 \%$ e $20 \%$ da capacidade desse órgão é disponibilizada para a produção diária de $150 \mathrm{mg}$ a $250 \mathrm{mg}$ de albumina por quilograma de massa corporal em indivíduos saudáveis ${ }^{9}$. É a mais abundante proteína plasmática, perfazendo um total de $50 \%$ das proteínas totais do soro humano, sendo o principal componente proteico na maioria dos líquidos biológicos extravasculares ${ }^{10}$.

Comparada a outras proteínas, é uma molécula relativamente pequena, formada por 584 aminoácidos. Assim, constitui um polipeptídio simples com massa molecular em torno de 69000 D, configurada predominantemente em $\alpha$-hélices sustentadas e unidas por pontes dissulfeto. A meia vida biológica da albumina é relativamente curta (15 a 20 dias). Seu conteúdo no plasma resulta do balanço entre a síntese, o catabolismo e a excreção. Cerca de um grama é perdido pelo trato gastrintestinal, e 0,4 grama, filtrado pelo rim, não sendo afetada pela presença das vitaminas e minerais. No entanto, sofre importantes quedas no caso de ingestão 
alimentar insuficiente e deficiência proteica prolongada ${ }^{8,9,10}$.

Assim, grosso modo, uma possível diminuição na concentração sérica das proteínas totais e albumina pode ser utilizada para detectar e caracterizar o estado da nutrição proteica e da saúde numa comunidade relativamente isolada.

Esta pesquisa tem por objetivo avaliar o nível de proteínas no sangue de índios Terena de Mato Grosso do Sul, determinando as proteínas totais e albumina que, em conjunto, caracterizam o estado de saúde e da qualidade de nutrição, em particular.

\section{Materiais e métodos}

O povo Terena, originário da Indonésia, pertencente ao subgrupo Guaná-Txaná e integrado à família linguística Aruak ${ }^{11}$, habita o Estado de Mato Grosso do Sul, pelo menos, desde o ano de $1649^{12}$. Os Terensa, em sua língua nativa, se autodenominam pokée - que significa terra - e são essencialmente agricultores, pois a maioria das famílias possui área variando entre 1 e 10 hectares com roças de milho, arroz, feijão, abóbora, melancia, batata-doce, mandioca, maxixe, entre outros, e a presença de árvores frutíferas próximas dos domicílios. As moradias são construídas, na sua maioria, de taquarussu e bacuris partidos ao meio e cobertos de sapê ou folhas de outras palmeiras encontradas na região; o piso é sem cobertura (chão batido) ${ }^{13}$. Quanto ao saneamento, todas as propriedades possuem água de poço artesiano comunitário, administrado pela Fundação Nacional de Saúde (Funasa), porém as próprias instalações sanitárias deixam muito a desejar ${ }^{14}$.

Este estudo refere-se à área indígena Buriti, localizada nos limites dos municípios de Sidrolândia e Dois Irmãos do Buriti, que inclui as aldeias denominadas Córrego do Meio, Lagoinha e Barreirinho, em uma área de 2.090 hectares e com população Terena estimada em 1.875 indígenas, segundo dados da Funasa ${ }^{2}$. Está inclusa também a aldeia Terena urbana, Tereré, localizada no município de Sidrolândia, no Estado de Mato Grosso do Sul. As aldeias foram selecionadas levando-se em consideração a localização acessível e o interesse da população indígena em participar na pesquisa dedicada à sua etnia.

Para que os futuros resultados dessa pesquisa possam fazer parte de uma discussão mais ampla e contribuam para formar bancos de dados etnográficos, aqui estão reproduzidas, com mais detalhes, as coordenadas das aldeias mencionadas para o estudo (Figura 1).

Trata-se de estudo transversal, cuja investigação foi levada a cabo entre fevereiro de 2007 e março de 2008. A amostra incluiu 285 indivíduos que concordaram em participar do estudo, de forma livre e esclarecida. O projeto conta com a devida aprovação do Comitê de Ética em Pesquisa da UFMS, sob protocolo número 1222.

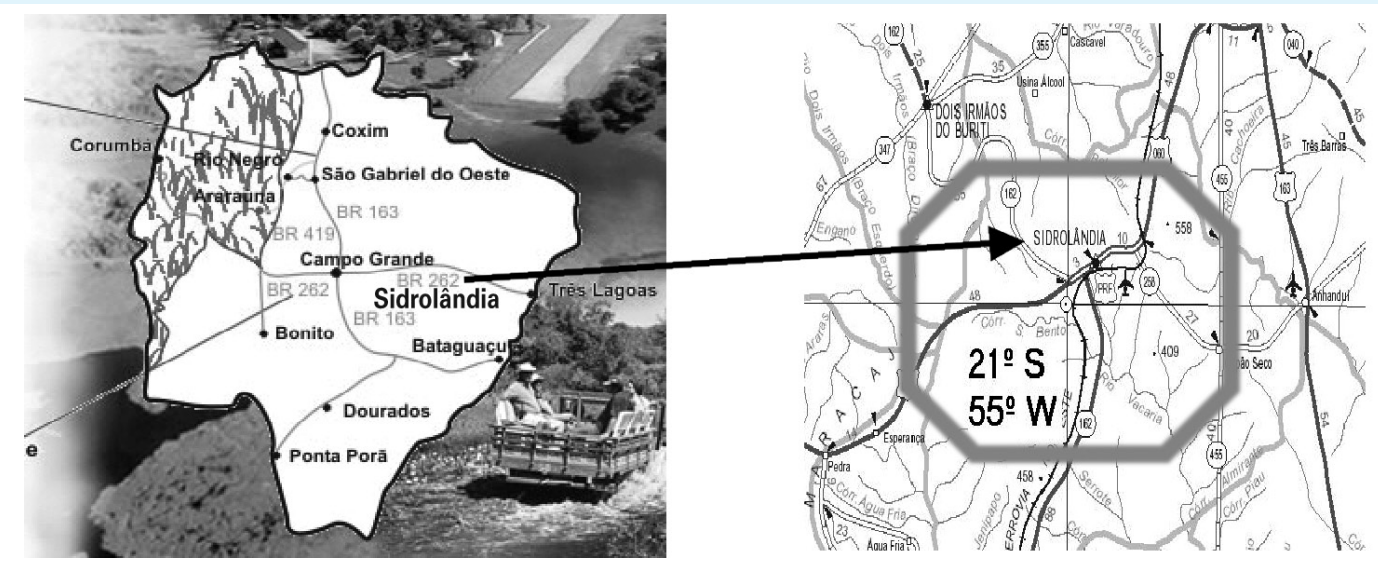

Figura 1: Mapa indicando a localização das aldeias Terena no Estado de Mato Grosso de Sul 
Foram adotados os seguintes critérios de exclusão: indivíduos que não alcançaram a idade de 20 anos e com doenças agudas e crônicas previamente diagnosticadas, pois neste último caso o teor das proteínas pode diminuir substancialmente.

As coletas de sangue foram feitas no período da manhã, em jejum, após repouso de 8 a 10 horas, no posto de saúde de cada aldeia. Foram usados tubos de poliestireno a vácuo, siliconizados sem anticoagulante. Após a centrifugação em 3000 RPM, foi obtido soro límpido, e as amostras armazenadas e congeladas a $-25^{\circ} \mathrm{C}$. Foi dada atenção para evitar o uso de amostras de sangue com sinais de hemólise e/ou lipêmicas, mesmo sendo procedentes dos participantes aparentemente sadios.

Para a determinação do conteúdo proteico foi usado o método colorimétrico, com leitura policromática de ponto final, e utilizado RXL Dade Behring automatizado. A quantidade das globulinas foi obtida pela diferença entre proteína total e albumina. Os valores de referência normalmente adotados para as proteínas totais e albumina são, respectivamente, 6,4 a $8,2 \mathrm{~g} / \mathrm{dl}$ e 3,4 a $5,2 \mathrm{~g} / \mathrm{dl}^{8}$.

Os resultados foram tabulados nos programas Microsoft Office Excel 2007 e BioEstat, versão 3.0 (Sociedade Civil Mamirauá, Manaus, Brasil).

\section{Resultados}

Na Tabela 1, estão representados os valores médios de proteínas com as características estatísticas correspondentes para 285 participantes.

Foram analisados 285 indivíduos, sendo 125 do sexo masculino, e 160, do feminino.
Neste trabalho, os valores das proteínas totais da população pesquisada apresentam média de $7,48 \mathrm{~g} / \mathrm{dl}( \pm 0,46)$ para sexo masculino, e 7,42 g/ $\mathrm{dl}( \pm 0,58)$, para o feminino, e para a albumina os valores médios obtidos foram $4,33 \mathrm{~g} / \mathrm{dl}( \pm 0,36)$ para o sexo masculino, e $4,17 \mathrm{~g} / \mathrm{d}( \pm 0,37)$, para o feminino, ou seja, permanecem de acordo com os valores de referência.

Quanto às proteínas totais e albumina, apenas $8(2,46 \%)$ dos indivíduos apresentaram valores abaixo da referência. Para as globulinas não houve nenhum caso de valores abaixo da referência.

\section{Discussão}

Em trabalho pioneiro realizado por Ribas et $a .^{13}$, relata-se que a atividade agrícola ainda é preservada, embora as áreas plantadas por família sejam pequenas. Com relação à alimentação, os índios Terena não têm horários rígidos. Foram observados que existem três refeições distribuídas como principais ao longo do dia, sendo a primeira, ao acordar, no nascer do sol; a segunda, no meio do dia, e a terceira, quando o sol se põe.

A dieta dos índios Terena está condicionada aos alimentos de menor custo e compõe-se basicamente de arroz, complementado pelo feijão, mandioca, milho, macarrão e carne. A carne, de difícil acesso, é bastante valorizada nas refeições. Para a maioria das famílias e, quando presente, é utilizada a de menor custo, naturalmente com elevado teor de gordura, preparada predominantemente na forma frita. $81,3 \%$ das famílias criam, em pequena escala, galinhas e porcos, consumidos em ocasiões especiais. Entre as refeições há consumo de frutos silvestres e tubérculos como a mandioca ou batata. Além

Tabela 1: Tabela com resultados da determinação das proteínas totais, albumina e globulinas

\begin{tabular}{c|c|c|c|c|c}
\hline \multirow{2}{*}{ Variáveis } & \multicolumn{2}{|c|}{ Média (g/d) } & \multicolumn{2}{c|}{ Desvio Padrão } & \multirow{2}{*}{$\begin{array}{c}\text { Valores abaixo do } \\
\text { referenciado }\end{array}$} \\
\cline { 2 - 5 } & $\mathbf{M}$ (n-125) & $\mathbf{F}$ (n=160) & $\delta$ & $q$ & $4(1,40 \%)$ \\
\hline Proteínas totais & 7,48 & 7,42 & 0,46 & 0,58 & $4(1,40 \%)$ \\
\hline Albumina & 4,33 & 4,17 & 0,36 & 0,37 & 0 \\
\hline Globulinas & 3,15 & 3,25 & 0,41 & 0,43 & \\
\hline
\end{tabular}


disso, as lideranças possibilitam que as famílias recebam mensalmente cestas básicas do poder público contendo produtos essenciais ${ }^{13,14,15,16}$.

Os valores de referência, normalmente utilizados para as proteínas totais e albumina, são, respectivamente, 6,4 a $8,2 \mathrm{~g} / \mathrm{dl}$ e 3,4 a 5,2 $\mathrm{g} / \mathrm{dl}$; os valores de carência branda, moderada e grave são habitualmente 2,8 a 3,5 g/dl, 2,1 a 2,7 g/dl e menos de 2,1 g/dl, respectivamente. Esses dados referem-se às grandes estatísticas da população mundial ${ }^{8,9,18}$. Assim, dos quatro indivíduos com valores de albumina baixos, dois podem ser caracterizados como tendo carência branda, e dois, moderada.

Embora a albumina sérica não seja um bom indicador da desnutrição, suas concentrações só caem após períodos prolongados de ingestão alimentar inadequada, embora, na recuperação nutricional, seus níveis normalizam-se lentamente com o aumento da ingestão alimentar ${ }^{17,18}$.

Ingesta insuficiente causa uma redução de 50\% na síntese hepática de albumina logo nas primeiras 24 horas $^{18}$. Além disso, o efeito da ingestão alimentar deficiente tem um impacto maior sobre a síntese de albumina do que sobre a das demais proteínas produzidas pelo fígado ${ }^{19,20,21}$.

Os dados obtidos deste trabalho permitem concluir que, do ponto de vista bioquímico, os índios Terena, que moram nos municípios de Sidrolândia e Dois Irmãos do Buriti, não apresentam anormalidades no metabolismo proteico, e o número de indivíduos que mostraram valores baixos não supera $2,46 \%$. Fica evidente que com outros indicadores nutricionais, tais como antropometria, composição corporal e consumo alimentar, esses dados contribuirão para uma avaliação fidedigna do estado nutricional dessa população.

\section{Conclusões}

1 Do ponto de vista bioquímico, os índios Terena que habitam a área indígena Buriti, localizada nos municípios de Sidrolândia e Dois Irmãos do Buriti, e a aldeia urba- na Tereré, no município de Sidrolândia, não apresentam qualquer anormalidade no metabolismo proteico e, portanto, não podem ser considerados como grupo subnutrido.

2 Apesar da precária condição socioeconômica das famílias, os hábitos do cotidiano, tais como a plantação de roças e a manutenção de árvores frutíferas próximas às casas, a adaptação cultural, a implantação de doação de cestas básicas pelo poder público, a relativa proximidade das aldeias da cidade e o acesso relativamente fácil, diferenciam essa população, no aspecto nutricional, em relação às outras etnias, principalmente as da região Norte do Brasil.

\section{Referências}

1. Barnes PM, Adams PF, Powell-Griner E. Health Characteristics of the American Indian and Alaska Native Adult Population: United States, 1999-2003, Division of Health Interview Statistics CDC. 2005 Apr. 27:356.

2. FUNASA. Sistema monitora saúde nas aldeias. Boletim especial. abril 2008:11.

3. FUNAI. Portal do cidadão. [Acesso em 20 nov. 2008]. Disponível em: http://www.funai.gov.br/mapas/ papa_etnia.htm.

4. Onís M, Monteiro CA, Akré J, Clungston G. The worldwide magnitude of protein-energy malnutrition: an overview from the WHO global database on child growth. Bull World Health Org. 1993;71(6):703-12.

5. Vieira - Filho JPB. A hemoglobina glicosilada $(\mathrm{Hb}$ A1) dos índios Xavantes. Arq Bras Endocrinol Metab. 1983;27:153-5.

6. Bloch KV, Coutinho ESF, Lôbo MSC, Oliveira JEP, Milech A. Pressão arterial, glicemia capilar e medidas antropométricas em uma população Yanomámi. Cad. Saúde Pública. 1993; 9(4):428-38.

7. Gimeno SGA, Rodrigues D, Pagliaro H, Cano EN, Lima, EES, Baruzzi RG. Perfil metabólico e antropométrico de índios Aruák, Mehináku, Waurá e Yawalapití, Alto Xingu, Brasil Central, 2000/2002. Cad. Saúde Pública. 2007;23(8):1946-54. 
8. Tietz NW, Burtis CA, Ashwood ER. Fundamentos de Química Clínica. 6 ${ }^{\mathrm{a}}$ Ed. Rio de Janeiro: Guanabara Koogan; 2008.

9. Doweiko JP, Nompleggi DJ. Role of albumin in human physiology and pathophysiology. JPENJ Parenter Enteral Nutr. 1991;15(2):207-11.

10. Rothschild MA, Oratz M, Schreiber SS. Albumin synthesis. N Engl J Med. 1972;286(14):748-50.

11. Sganzerla A, Silva NG. A epopéia Terena. Campo Grande: UCDB;2004.

12. Gadelha R. As missões jesuíticas do Itatim: Estruturas sócio-econômicas do Paraguai colonial nos séculos VI e XVII. Rio de Janeiro: Paz e Terra;1982.

13. Ribas DLB, Sganzerla A, Zorzatto JR, Philippi ST. Nutrição e saúde infantil em uma comunidade indígena Terena, Mato Grosso do Sul, Brasil. Cad Saúde Pública. 2001;17(2):323-44.

14. Fávaro T, Ribas DLB, Zorzatto JR, Segall-Corrêa AM, Panigassi G. Segurança alimentar em famílias indígenas Terena, Mato Grosso do Sul, Brasil. Cad. Saúde Pública. 2007;23(4);785-93.

15. Ribas DLB, Philippi ST, Tanaka ACD'A., Zorzatto JR. Saúde e estado nutricional infantil de uma população da região Centro-Oeste do Brasil. Rev. Saúde Pública. 1999;33(4):358-65.
16. Ribas DLB, Philippi ST. Aspectos alimentares e nutricionais de mães e crianças indígenas Terena, Mato Grosso do Sul. In: Coimbra CEA Jr, Santos RV, Escobar AL. Epidemiologia e saúde dos povos indígenas no Brasil. Rio de Janeiro: Editora Fiocruz/ ABRASCO;2003.

17. Fuhrman MP. The albumin-nutrition connection: separating myth from fact. Nutrition. 2002; 18(2):199-200.

18. Mora RJ. Malnutrition: organic and functional consequences. World J Surg. 1999;23(6):530- 5.

19. Dionigi R, Cremaschi RE, Jemos V, Dominioni L, Monico R. Nutritional assessment and severity of illness classification systems: a critical review on their clinical relevance. World J Surg. 1986;10:2-11.

20. Bistrian BR. Role of the systemic inflammatory response syndrome in the development of proteincalorie malnutrition in ESRD. Am J Kidney Dis. 1998;32(6 Suppl. 4):113-7.

21. Corrêa Camila Renata, Angeleli Aparecida Yooko Outa, Camargo Nádia dos Reis, Barbosa Luciano, Burini Roberto Carlos. Comparação entre a relação PCR/albumina e o índice prognóstico inflamatório nutricional (IPIN). J. Bras. Patol. Med. Lab. 2002;38(3):183-190. 